\title{
Student Responses to Learning Using Blended Learning Method: Study of Political Behavior Theory Subject at the Faculty of Social and Political Sciences Andalas University
}

\author{
Asrinaldi $^{1 *}$, Tengku Rika Valentina ${ }^{1}$
}

\author{
${ }^{1}$ Department of Political Science, Andalas University, Padang, West Sumatra, Indonesia \\ * Corresponding author: E-mail: asrinaldi@soc.unand.ac.id
}

\begin{abstract}
This article explains how students of the Political Science Department, FISIP, and Andalas University follow the Political Behavior Theory (TPP) course using the Blended Learning method. This study used a descriptive quantitative approach through a survey to determine student responses related to the use of the Blended Learning method in TPP courses. This study found that only 58.5 percent felt that the Blended Learning method increased their understanding of lecture materials. This response is certainly not surprising because not all students are familiar with learning using the Blended Learning method. This research found that 73.6 percent of students admit that this Blended Learning method forms their learning independence. Although not all of them are accustomed to learning independently, this Blended Learning method still needs to be combined with conventional methods to complement the Blended Learning method's shortcomings.
\end{abstract}

Keywords: Blended learning method, student participant, university, and method combination

\section{INTRODUCTION}

Useful learning methods are a requirement for graduate learning outcomes. However, not many teachers, such as lecturers and teachers, pay attention to appropriate learning methods, such as communication and information technology, in tertiary institutions known as the Blended Learning method. Garrison and Kanuka (2004) [1] argue that Blended Learning is an effective and low-risk learning method that universities will continue to use. Moreover, the development of communication and information technology requires universities to reform learning methods by leaving classroom learning methods. This article aims to explain student responses related to the use of Blended Learning in lectures. So far, lecturers who are teaching subjects have only used conventional methods in explaining the material in class subjects.
Moreover, this course is a theoretical course that makes the participants feel difficult to understand, so they are not interested in understanding it more deeply. Besides, students' feeling of boredom and laziness is also a problem for lecturers to realize their graduates' learning outcomes. One of the reasons is the monotonous and uncreative learning methods that reduce student interest and attention in lectures. Therefore, the Blended Learning method is an alternative to increase student interest in learning materials provided by teachers in tertiary institutions. This phenomenon can occur due to a combination of classroom training using communication and information technology [2]. The Blended Learning method is a learning method that combines face-to-face lectures with learning using communication and information technology. This combination is intended to give students the freedom to study independently, free to use their real abilities. In short, learning with the Blended Learning method is very interactive and flexible in terms of time and place [3]. 
For teachers such as lecturers in universities, using the Blended Learning method is indeed a challenging choice. However, they consciously know the many advantages of this Blended Learning method. Besides, the Blended Learning method can also improve graduates' achievement so that they have competencies appropriate to the world of work. On the other hand, as a new learning method for students, not all of these methods can help them understand learning material well. It is precisely in this Learning that students must be independent and responsive to the existing material. Another problem with the Blended Learning method is the availability of facilities and infrastructure that support the learning process. This article explains how student responses are related to the use of this learning method. Also, to find out how these students can compare this method's strengths and weaknesses, this study compares the experiences of students who receive learning through the classroom learning method with the online learning method. The process is that students taking the Political Behavior Theory course are given course material 14 times apart from the midterm and final semester exams. Two sessions are applied to students in its implementation, namely by mixing learning methods, seven meetings conducted with the class's learning method, and seven meetings with learning using the eLearning method. This study assumes that not all students are familiar with the Blended Learning method because they are passive lectures and receive from lecturers who teach using classroom learning methods. They do not have a strong interest and motivation to develop learning materials independently. Besides, they also find it challenging to follow this learning process because students are not familiar with learning using this eLearning method. Internet network problems and limited access to the internet also impact the application of the Blended Learning method.

\section{BLENDED LEARNING AND ITS CONTENT}

\subsection{Use Blended Learning}

It cannot be denied that the implementation of elearning or online Learning is part of the advancement of learning technology. Almost all universities in the world are familiar with this method. So far, learning methods using conventional methods have begun to be reduced because they are considered ineffective and efficient in terms of space and time utilization [4]. According to Garisson \& Vaughan (2008)[2], the Blended Learning method's use produces a unique learning experience for students and can fulfill the learning process and realize learning goals. In some cases, this conventional (offline) learning method cannot be eliminated because, in several aspects presenting face-to-face Learning and classroom training is still needed, especially in training student psychomotor. Because this blended learning method uses the internet, many lecturers or teachers do not believe in this system. Because this learning process will encounter many obstacles and problems, especially when using online Learning - likewise, weaknesses in dealing with student learning problems that cannot be resolved directly. For example, this is related to changes like technology, the network system's complexity, and the lack of stability in the online learning environment. When implementing, it encounters difficulties [5].

However, the fact is that many universities have not been able to take advantage of advances in communication and information technology. There is no option for universities to adopt this learning method. One of them is combining classroom learning methods with this network method. One of the advantages of this Blended Learning method is that it makes it easy for students. That is, they are not bound by time and space. There are advantages for students when attending lectures using this learning method, especially in other activities that they can participate in off-campus without leaving the lectures they must take to become a bachelor. With learning methods that are more flexible, interactive, and cost-effective, the implementation of this Blended Learning method in the future will increasingly get a place in the learning system in higher education [6], [7]. This Blended Learning method also gives students the flexibility to develop critical student thinking, encourage students to be more active, increased student attention to problem-solving and other higher-order thinking skills. Meanwhile, these advantages are not owned by conventional learning methods or classroom training.

Not only that, in the context of the independent learning program, which is the policy of the Ministry of Education and Culture, the use of blended Learning is certainly very appropriate. Flexible students can adjust themselves to their activities in exploring their potential. For example, they can learn while practicing the material they get in their daily lives. Besides, students can also criticize the concepts/theories taught in lectures with the field's realities. Thus, students have a broader space to explore their thoughts related to the material they are studying. On the other hand, combining eLearning learning methods with classroom training methods helps students measure their achievements by comparing these two learning methods in one Blended Learning method.

The use of the blended learning method is an alternative and a solution for teachers who face classroom training learning problems. Learning with this conventional method looks passive and centered on the lecturer, thus ignoring student creativity. Indeed, not all classroom training methods have weaknesses, as many have criticized them. Many lecturers, teachers, and researchers realize that this conventional method can build emotional relationships with students to understand 
how the learning process occurs. This aspect does not exist in eLearning learning. Blended Learning tries to combine these two methods to complement each other to realize these learning outcomes.

Therefore, according to Graham (2006)[4], efforts to combine learning methods are determined by the goals to be achieved. This mixture of methods can be divided into three forms, each of which has a different purpose. For example, first, enabling blends: a mix intended to focus on overcoming problems related to online technology access and convenience for learners; Second, enhancing blends: blends intended to allow some changes in the way of teaching, such as the inclusion of some online supplementary material in traditional face-to-face systems; and third, transforming blends: a mixture intended for a radical transformation of the teaching method, such as a change from a model where students are only recipients of information to a model where learners actively build knowledge through dynamic interactions.

\subsection{Weaknesses of Blended Learning and Its Impact on Learning}

The explanation above certainly does not confirm that this blended Learning is the best and has no weaknesses. Besides having advantages, this Blended Learning method also has weaknesses that can interfere with learning objectives. The fundamental problem in implementing Blended Learning, especially eLearning, as explained by Burbles (2004) [8], is related to hidden barriers in accessing virtual classes for some students. Students also have limitations in accessing online classes for various technical reasons. Even some learning applications are not suitable for students, and the availability of communication media that can be used by all students is limited.

Even for some developing countries, the internet network infrastructure is essential to increase this eLearning success. For example, Indonesia is a country that still has problems with internet network infrastructure. Even in many areas, there are still areas that have not been reached by the internet network. The absence of this network is one of the critical problems in using this eLearning. Another technical problem is students' ability to use information and communication technology, which is still much below average. Because in some hardware and software, such as applications used in eLearning, students' ability to use them is required. Sometimes this problem becomes a problem, and it is difficult for students to solve. Students will also face "isolation" in the learning process in the psychological aspect, which also impacts the expected learning outcomes. Usually, students who use eLearning quickly become bored because they are learning without any direct interaction. Therefore, it needs to overcome this problem. The Blended Learning method is a mixture of strategy and technology and a holistic didactic method that combines the effectiveness and opportunities of classroom socialization with the possibility of active Learning by utilizing technology from the online environment. Therefore, there needs to be a combination with traditional classroom learning that can excite frustrated students in facing eLearning classes. This problem will affect student learning outcomes. Indeed, besides the advantages of using the Blended Learning method, students also face other problems. For this reason, every lecturer who uses the Blended Learning method, especially when using eLearning, must be able to find solutions to problems that arise so that the learning objectives using this method are achieved.

\section{RESEARCH METHOD}

This study uses a quantitative approach that emphasizes quantifying phenomena related to student learning using the BL method. The research process begins by dividing lectures using two models of lecture implementation as characteristic of BL, namely face-toface classes before the Mid-Semester Examination (UTS) and lectures using the eLearning learning method, namely lectures that are carried out after midterm exams. Moreover, it ends before the implementation of the Final Semester Examination (UAS). The evaluation of these two methods' use is by comparing the UTS results and the UAS, which are part of the evaluation of the use of each of these methods. This study's data were obtained from students who attended this lecture through a questionnaire that they issue at the end of the lecture. This questionnaire is filled out online using the google form service. The questionnaire contains questions about the substance, mechanism, and evaluation of learning in this Political Behavior Theory course. The questionnaire was distributed using the lecture group Whatsapp to get responses and answers from the students participating in the course. Of the 71 students participating in the course, only 53 questionnaires responded to the researcher. Students who did not fill out the questionnaire were generally those who had problems with the internet network when filling out the questionnaire.

\section{RESULTS AND DISCUSSION}

Although many researchers have found advantages in using this learning method using Blended Learning, the fact is that this method also still has problems. The evaluation of students' learning outcomes taking this course is not following the outstanding achievement. This study proves that students get real differences when this course ends, especially from the final grades of students who take this course. It is admitted that many factors determine the success of Blended Learning. The 
infrastructure must be available, and human learners, such as their motivation, commitment, and independence in participating in learning using this method.

By the experimentation carried out on this lecture, in particular comparing the processes and results obtained by students using the Blended Learning method. The evaluation of this method's use, namely the lecture process using classroom learning for half a semester and learning on the internet network (eLearning), can be seen in the UTS and UAS results obtained by students. Indeed, the evaluation results are sufficient to describe the inequality of achievements obtained by students using these two learning methods, which can be seen in the following table.

Table 1. Comparison of the values of political behavior theory by using two learning methods

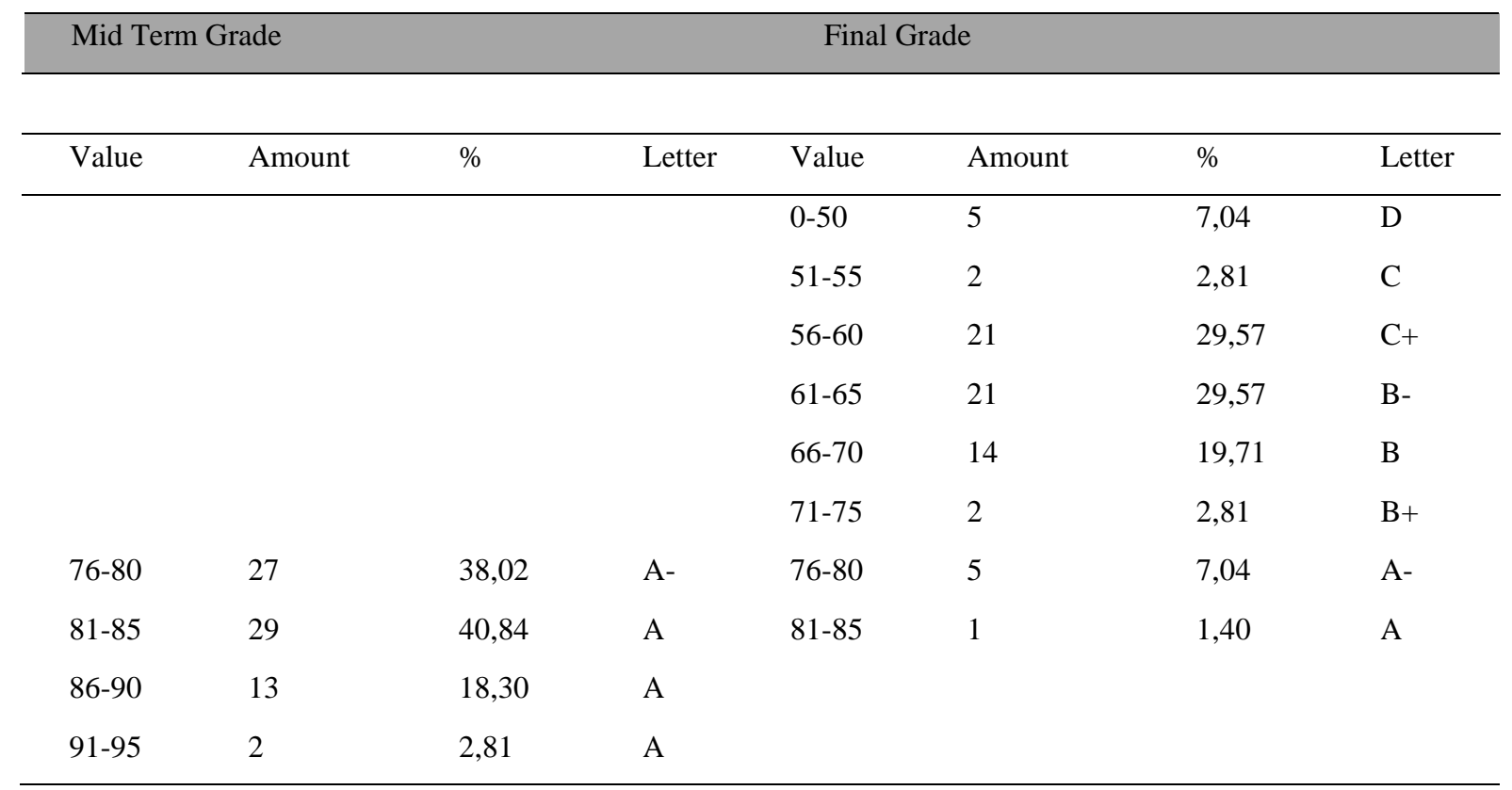

By comparing the two scores obtained by these students, it can be seen that there are still problems with the use of this Blended Learning method, especially in Learning using e-Learning. Learning evaluation is carried out through the implementation of UTS to see learning outcomes using face-to-face activities. The habits of students who have used the direct face-to-face learning approach still significantly influence their understanding. Indeed, learning using Blended Learning is something new for students to affect their understanding of the material. It can be seen from the results of the evaluation obtained by students at the UAS. Blended Learning that started after UTS by utilizing eLearning such as i-Learn, zoom meeting, and skype could not improve their understanding. Of course, this is a problem that needs a solution. Given that Learning using Blended Learning is the primary method of learning in the future.

This study focuses on student responses to course material given to them, especially after UTS. Student admissions do vary with eLearning, as can be seen from the UAS results, as shown in Table 1 above. The distribution of UAS scores obtained by students illustrates how students learn and understand the material being taught. It can be seen that only 11.25 percent of students get right and excellent results. Meanwhile, the others are below that. This condition needs to be explored why students only get results like that. The following can be explained some explanations based on student responses who were asked after the lecture ended via a google form, which was distributed to them.

\section{a. Student identity}

Indeed, not all students responded to the questions sent via the google form. One of the reasons that emerged was that students had difficulty accessing the form because of their limited signals. This condition also affects their response to questions sent via google form that they must fill out. Of the 71 students who took part in the lecture, only about 53 students successfully responded to the evaluation of this e-Learning learning process. Of these, 98.1 percent take this course for the first time or are students with the 2017 student number (No.BP). 
b. Can attend lectures with eLearning

Interestingly, students who take this course admit that they can attend lectures using eLearning. There are no obstacles to lectures using this method so that students can follow these lectures well. The obstacles that interfere with this lecture come from factors outside of themselves. Such as lousy internet signal and limited availability of student data packages when attending lectures using this method.

Table 2. Student responses to lectures using eLearning

\begin{tabular}{ll}
\hline Response & Percentage $(\%)$ \\
\hline Strongly agree & 7,5 \\
Agree & 79,2 \\
Disagree & 9,4 \\
Totally Disagree & 3,9 \\
\hline & $\mathrm{n}=53$ people \\
\hline
\end{tabular}

c. Made several changes in study habits

Indeed, since the COVID-19 Pandemic, the elearning method has become the choice for educational institutions, including universities. However, e-Learning requires a change in student learning habits. Almost all students who take this course feel the need to make changes to their learning habits that have been carried out so far. Table 3 below illustrates students' responses to changes in their learning habits.

Table 3. Student responses that require changes in learning habits

\begin{tabular}{ll}
\hline Response & Percentage $(\%)$ \\
\hline Strongly agree & 22,6 \\
Agree & 75,5 \\
Disagree & 1,9 \\
Totally Disagree & - \\
\hline & $\mathrm{n}=53$ people \\
\hline
\end{tabular}


Indeed, the learning process using e-Learning requires adjustments because students are no longer dealing directly with their lecturers. They must be independent and have the initiative to start learning by using the lecturer's directions and materials using the provided i-Learn platform. Moreover, learning courses using the e-Learning method are also not synchronous or, at the same time, taking part in lectures. This change in learning habits determines students' success in realizing the learning outcomes that have been determined.

The following table can explain the responses of students who agree that Blended Learning using eLearning makes students more independent in learning this subject. As many as 73.6 percent of them agree that eLearning causes them to be independent in Learning.

Table 4. Student responses related to their independence in Learning

\begin{tabular}{ll}
\hline Response & Percentage (\%) \\
\hline Strongly agree & 9,4 \\
Agree & 64,2 \\
Disagree & 24,5 \\
Totally Disagree & 1,9 \\
\hline & $\mathrm{n}=53$ people \\
\hline
\end{tabular}

There are still many students who find it challenging to understand learning materials using this e- Learning method. More than 35.8 percent of students find it challenging to understand the material being taught for this subject. See the distribution, as shown in Table 5 . below.

Table 5. Student responses related to the relationship between eLearning and increased understanding

\begin{tabular}{ll}
\hline Response & Percentage $(\%)$ \\
\hline Strongly agree & 1,9 \\
Agree & 58,5 \\
Disagree & 35,8 \\
Totally Disagree & 3,8 \\
\hline & $\mathrm{n}=53$ people \\
\hline
\end{tabular}

Another thing that has also changed is the problem of student motivation in attending lectures. In following the Blended Learning method, students must have a strong motivation to use it. As many as 73.6 percent agreed with their increased motivation to learn. The following table can be seen how the student responses related to their increase in motivation.

Table 6. Student responses related to increasing their motivation to learn

\begin{tabular}{ll}
\hline Response & Percentage $(\%)$ \\
\hline Strongly agree & 9,4 \\
Agree & 64,2 \\
Disagree & 22,6 \\
Totally Disagree & 3,8 \\
\hline & $\mathrm{n}=53$ people \\
\hline
\end{tabular}


The same thing can also be seen from the increased

interaction space between students and lecturers in learning using eLearning, as shown in Table 7.

Table 7. Student responses related to increasing student interaction space with students and lecturers

\begin{tabular}{ll}
\hline Response & Percentage $(\%)$ \\
\hline Strongly agree & \\
Agree & 7,5 \\
Disagree & 52,8 \\
Totally disagree & 39,6 \\
\hline & - \\
\hline
\end{tabular}

\section{d. Choice and Convenience with Blended Learning}

This study also evaluates the implementation of this Blended Learning method by introducing eLearning students to their strengths and weaknesses. This study evaluates the tendency of students to choose the method that suits them. Do they prefer eLearning, which is synonymous with Blended learning or classroom training? It turns out that there are still many students who do not agree to use eLearning. The fact is that more students choose to use classroom training instead of eLearning in Learning. Table 8 below can describe the student's response.

Table 8. Responses to student choice approval on eLearning

\begin{tabular}{ll}
\hline Tanggapan & Percentage $(\%)$ \\
\hline Strongly agree & 3,8 \\
Agree & 43,4 \\
Disagree & 47,2 \\
Totally disagree & 5,6 \\
\hline & $\mathrm{n}=53$ people \\
\hline
\end{tabular}

e. More effort from students to study independently for material enrichment

The consequence of using eLearning is that students must take the initiative and actively learn independently to find other sources to enrich lecturers' material in the Learning. This material enrichment can support students in realizing the learning objectives of the course Therefore, learning with this eLearning method requires students to find additional material according to their needs and initiatives. Data showed that 80 percent of students agree that they are also looking for additional material beyond what is taught by the lecturer. Table 9 below illustrates this trend. 
Table 9. Student responses related to independent Learning to complement the course material provided

\begin{tabular}{ll}
\hline Tanggapan & Percentage $(\%)$ \\
\hline Strongly agree & 5,6 \\
Agree & 77,4 \\
Disagree & 15,1 \\
Totally disagree & 1,9 \\
\hline & $\mathrm{n}=53$ people \\
\hline
\end{tabular}

From the students' responses, it can be concluded that they are generally quite enthusiastic about this Blended Learning method. Although from the other side, there are also weaknesses that make students disagree with using this method. This study tries to map how student responses, in general, are related to the use of this Blended Learning. There is a question that is asked, "If you were given a satisfaction rating from range 1-10 to the Political Behavior Theory using Blended Learning, what position are you in?" Below can be seen in their answers.

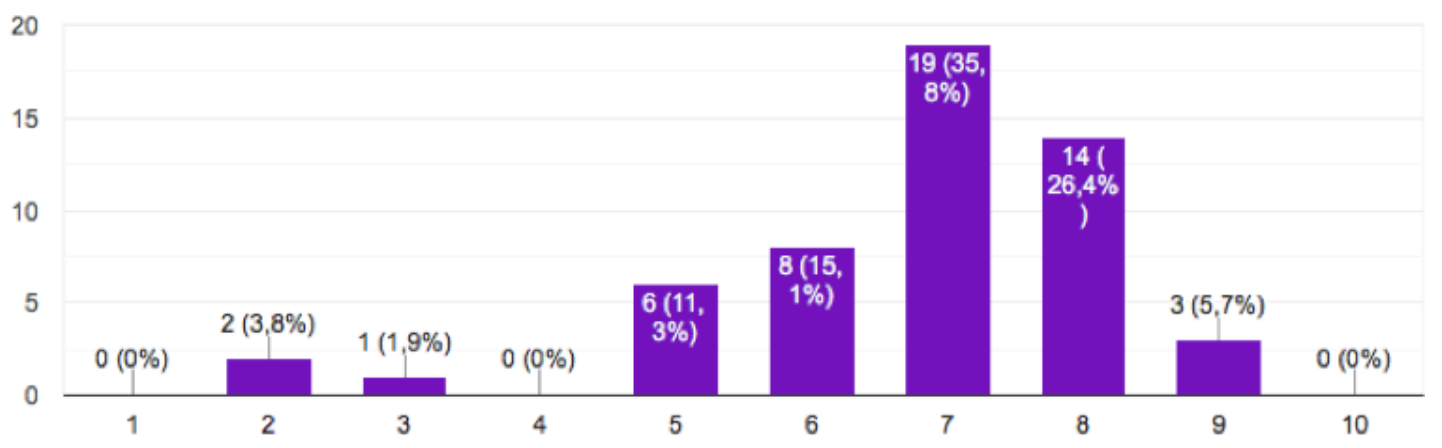

Figure 1. Student assessment of the use of Blended Learning

From the picture above, it can be seen that the distribution of students' answers regarding their responses using the Blended Learning method, especially the use of e- Learning. In general, students are at a new stage in getting to know this e-Learning method. Of course, this is the initial picture to continue introducing the eLearning method in this Blended Learning by fixing all the weaknesses students complain about.

\section{CONCLUSION}

The discussion in this article shows that the use of the Blended Learning method in the Theory of Political Behavior has not been going well. Learning evaluation results by comparing Learning using conventional methods through classroom training activities with eLearning is in stark contrast. Students feel comfortable using classroom training, which is shown by the maximum UTS results. Meanwhile, when they are taught using the e-Learning method, they get results that are far below the results using the classroom training method. This study found many students' problems when responding to Learning using e -Learning, for example, regarding their unfamiliarity with this eLearning method. Besides, internet infrastructure problems impact their limited access, impacting the Blended Learning method has expected outcomes and outcomes.

The Blended Learning method is a learning method that has received mixed responses from lecturers and students. In general, students responded positively to the use of Blended Learning. As a new learning method, it needs to improve its existing weaknesses by identifying eLearning, which is the character of Blended Learning in this course as follows. First, there needs to be infrastructure readiness, such as signal availability, devices used, and platforms explicitly used to support this Blended Learning implementation. Second, there needs to be a complete explanation given by the subject lecturer to follow instructions in understanding the material provided. Also, lecturers' recommendations are needed 
relating to other materials that students can study. Third, lecturers must identify the weight of the learning material to be taught to students because this is related to the learning outcomes that will be realized. There are more comfortable materials for students to understand through face-to-face Learning (classroom training), and there are aterials that can indeed be provided through eLearning. Fourth, there needs to be a course RPS preparation that can follow how students' substance can be understood and how to use effective media to realize graduate learning outcomes.

\section{ACKNOWLEDGMENT}

This research was funded by LP3M Universitas Andalas with the contract number T.06/UN.16.18/PT.01.03 / 2020

\section{REFERENCES}

[1] Garrison, D. Randy, and Kanuka, Heather, (2004), Blended Learning: Uncovering Its Transformative Potential In Higher Education, Internet, and Higher Education, 7, pp. 95-105.

[2] Garrison, D. Randy and Vaughan, Norman D, (2008), Blended Learning in Higher Education: Framework, Principles, and Guidelines. San Francisco, CA: John Willey \& Sons, Inc.

[3]Paetchter, M. \& Maier, B., 2010. Online or faceto- face? Student experiences and preferences in e- learning. Internet and Higher Education, 13, pp 292-297.

[4] Graham, C. R., 2006. Blended Learning System: Definition, Current Trend, and Future Directions. In C. J. Bonk \& C. R. Graham (Eds), The Handbook of Blended Learning; Global Perspectives, Local Designs. San Fransisco, CA: Pfeiffer.

[5] Conlon, T. (1997) The Internet is not a panacea. Scottish Educational Review, 29(1), 30-38.

[6] MacDonald, J., 2008. Blended Learning And Online Tutoring, 2nd ed. Hampshire, UK: Gower.

[7] Mitchell, P. \& Forer, P., 2010. Blended Learning: The Perception Of First-Years Geography Student. Journal of Geography in Higher Education, 34(1), pp. 77-89.

[8] Burbles, N. C. (2004), Navigating the Advantages and Disadvantages of Online Pedagogy. In Haythornthwaite, C., and Kazmer, M. M. (Eds.) Learning, Culture, and Community in Online Education: Research and Practice. New York: Peter Lang Publishing, pp. 1-17. 